\title{
Perspectivismo: "tipo" ou "bomba"?
}

\author{
Bruno Latour II \\ Tradução de Larissa Barcellos*
}

\section{Paris, 30 de janeiro}

Quem disse que a vida intelectual de Paris estava morta? Quem disse que a antropologia não mais era vívida e atraente? Aqui estamos, numa fria manhã de janeiro, em uma sala cheia de pessoas de diversas disciplinas e de vários países, ávidas por ouvir um debate entre dois dos maiores e mais brilhantes antropólogos ${ }^{1}$. 0 rumor circulou por salas de bate-papo e cafés: depois de anos fazendo alusões aos seus desacordos, em particular ou por publicações, eles concordaram enfim em trazê-los a público. "Vai ser áspero", me disseram; "vai ter sangue". Na verdade, em vez da rinha esperada por alguns, a pequena sala na Rue Suger testemunhou uma disputatio, muito parecida com aquelas que devem ter tido lugar entre estudiosos fervorosos aqui, no coração do Quartier Latin, por mais de oito séculos.

Apesar de se conhecerem há 25 anos, os dois decidiram começar sua disputatio lembrando à plateia acerca do importante impacto do trabalho um do outro em suas próprias descobertas.

Philippe Descola primeiramente reconheceu o quanto ele aprendeu com Eduardo Viveiros de Castro quando estava tentando se extirpar do binarismo "natureza versus cultura" ao reinventar a então obsoleta noção de "animismo" para entender modos diferentes de relação entre humanos e não humanos. Viveiros de Castro havia proposto o termo "perspectivismo" para um modo que não poderia ser mantido dentro das limitadas estrituras de natureza versus cultura, já que, para

\footnotetext{
I Nota dos editores: Esta é uma tradução do artigo "Perspectivism: 'type' or 'bomb'?", publicado originalmente pelo periódico Anthropolgy Today, vol. 25, n. 2, p. 1-2, 2 abr. 2009. Revisão técnica da tradução realizada por Marta Amoroso.

II Bruno Latour é professor no Institut d'Études Politiques (Sciences Po) em Paris. Seu website é

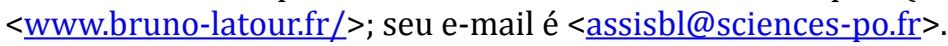

* Graduanda em Ciências Sociais - USP.

1 "Perspectivismo e animismo": debate entre Philippe Descola (Collège de France) e Eduardo Viveiros de Castro (Museu Nacional do Rio de Janeiro), Maison Suger, Instituto de Estudos Avançados, Paris, 30 de janeiro de 2009.
} 
os índios que ele estava estudando, a cultura humana é aquilo que vincula todos os seres - incluindo animais e plantas - ao passo que os seres estão divididos por suas diferentes naturezas, ou seja, seus corpos (VIVEIROS DE CASTRO,1992).

É por esse motivo que, enquanto os teólogos em Valladolid debatiam acerca dos índios terem ou não uma alma, esses mesmos índios, do outro lado do Atlântico, testavam os conquistadores ao afogá-los para ver se apodreciam - uma bela maneira de ver se eles realmente tinham um corpo; o fato de terem uma alma não estava em questão. Esse famoso exemplo de antropologia simétrica levou LéviStrauss a notar, com uma certa ironia, que os espanhóis poderiam ser bons em ciências sociais mas que os índios estavam conduzindo suas pesquisas de acordo com o protocolo das ciências naturais.

\section{Os quatro modos de relação de Descola}

Descola, então, explicou como a sua nova definição de animismo poderia ser utilizada para distinguir "naturalismo" - a visão geralmente tida como posição padrão adotada pelo pensamento ocidental - de "animismo". Enquanto os "naturalistas" traçam semelhanças entre entidades com base em aspectos físicos e os distinguem com base em características mentais ou espirituais, o "animismo" toma a posição oposta, sustentando que todas as entidades são semelhantes em termos de seus aspectos espirituais, mas se diferem radicalmente em virtude do tipo de corpo do qual são dotadas.

Esse foi um avanço notável para Descola, já que significou que a divisão "natureza versus cultura” não mais constituía o background inevitável adotado pelo ofício como um todo, mas apenas uma das maneiras que os "naturalistas" tinham de estabelecer as suas relações com outras entidades. A natureza deixou de ser um recurso para se tornar um assunto. Desnecessário dizer, essa descoberta não estava perdida em nossas próprias, no campo vizinho dos science studies, que estudávamos, histórica ou sociologicamente, como os "naturalistas" tratavam as suas relações com não humanos.

Foi então possível para Descola, como ele explicou, adicionar a esse par de conexões contrastantes um outro par no qual as relações entre humanos e não humanos eram ou semelhantes em ambos os lados (o que ele chamou "totemismo") 
ou diferentes nos dois lados (um sistema por ele denominado "analogismo") . Em vez de cobrir o globo com um único modo de relações entre humanos e não humanos que então serviria como um background para detectar as variações "culturais" entre muitos povos, esse mesmo background virara objeto de cuidadosa investigação. Os povos não se diferem apenas em suas culturas mas também em suas naturezas, ou antes, na maneira pela qual eles constroem relações entre humanos e não humanos. Descola foi capaz de alcançar o que nem os modernos nem os pós-modernos conseguiram: um mundo livre da unificação espúria de um modo naturalista de pensar.

Apesar do universalismo imperialista dos "naturalistas" ter sido ultrapassado, um novo universalismo ainda era possível, um que permitisse que cuidadosas relações estruturais fossem estabelecidas entre as quatro maneiras de produzir coletivos. 0 grande projeto de Descola era então reinventar uma nova forma de universalismo para a antropologia, mas dessa vez um "relativo", ou antes, um universalismo "relativista", que ele desenvolveu em seu livro Par delà nature et culture (2005). A seu ver, Viveiros de Castro estava mais focado na exploração profunda de apenas um dos contrastes locais que ele, Descola, tentara contrastar com numerosos outros ao lançar a sua rede mais amplamente.

\section{Duas perspectivas sobre o perspectivismo}

Apesar de serem amigos por um quarto de século, duas personalidades não poderiam ser mais distintas. Depois do tom aveludado da apresentação de Descola, Viveiros de Castro falou por breves aforísticas incursões, lançando uma espécie de Blitzkrieg em todas as frentes a fim de demonstrar que também ele pretendia atingir uma nova forma de universalismo, só que uma ainda mais radical. 0 perspectivismo, do seu ponto de vista, não deveria ser considerado como uma simples categoria dentro da tipologia de Descola, mas antes como uma bomba, com o potencial de explodir toda a implícita filosofia tão dominante na maior parte das interpretações dos etnógrafos sobre seus materiais. Se há uma abordagem que é totalmente antiperspectivista é a noção mesma de um tipo dentro de uma categoria, uma ideia que só pode ocorrer àqueles a quem Viveiros de Castro chamou "antropólogos republicanos". 
Como Viveiros de Castro explicou, o perspectivismo virou algo como uma moda nos círculos amazônicos, mas essa moda oculta um conceito muito mais incômodo, que é o de "multinaturalismo". Enquanto os pesquisadores, tanto das ciências duras quanto das ciências humanas, concordam igualmente com a noção de que há apenas uma natureza e muitas culturas, Viveiros de Castro quer levar o pensamento amazônico (que não é, ele sustenta, a "pensée sauvage" que LéviStrauss sugeriu, mas uma filosofia totalmente domesticada e altamente elaborada) a tentar ver como o mundo inteiro seria se todos os seus habitantes tivessem a mesma cultura e muitas naturezas diferentes. A última coisa que Viveiros de Castro pretende é que a luta ameríndia contra a filosofia ocidental se torne apenas mais uma curiosidade no vasto gabinete de curiosidades que ele acusa Descola de estar tentando construir. Descola, ele argumenta, é um "analogista" - isto é, alguém que é possuído pelo cuidadoso e quase obsessivo acúmulo e classificação de pequenas diferenças a fim de preservar um senso de ordem cósmica ante a constante invasão de diferenças ameaçadoras.

Notem a ironia aqui - e a tensão e atenção na sala aumentaram neste momento: Viveiros de Castro não estava acusando Descola de estruturalista (uma crítica que foi frequentemente dirigida a seu maravilhoso livro), já que o estruturalismo, como Lévi-Strauss o concebe, é, ao contrário, "um existencialismo ameríndio", ou antes "a transformação estrutural do pensamento ameríndio" como se Lévi-Strauss fosse o guia, ou melhor, o xamã que permitiu ao perspectivismo indígena ser conduzido para dentro do pensamento ocidental a fim de destruí-lo a partir de seu interior, numa espécie de canibalismo invertido. LéviStrauss, longe de ser o frio, racionalista catalogador de mitos distintos contrastados, aprendera a sonhar e divagar como os índios, exceto que ele sonhava e divagava por meio de fichas e parágrafos finamente torneados. Mas o que Viveiros de Castro criticou foi que Descola arrisca tornar a transformação de um tipo de pensamento para outro "demasiadamente leve", como se a bomba que ele, Viveiros de Castro, queria colocar na filosofia ocidental tivesse sido desarmada. Se nós permitíssemos ao nosso pensamento se conectar à alternativa lógica ameríndia, toda a noção dos ideais kantianos, tão difusa nas ciências sociais, teria que ser descartada. 
A essa crítica Descola respondeu que ele não estava interessado no pensamento ocidental, mas no pensamento de outros; Viveiros de Castro replicou que a sua maneira de estar "interessado" é que era o problema.

\section{Pensamento descolonizador}

O que está claro é que esse debate destrói a noção de natureza como um conceito universal que cobre o globo, por conta do qual os antropólogos têm o muito triste e limitado dever de adicionar o que quer que tenha restado de diversidade sob a velha e desgastada noção de "cultura". Imaginem como os debates entre antropólogos "físicos" e "culturais" podem ficar quando a noção de multinaturalismo for levada em consideração. Descola, não obstante, ocupa a primeira cadeira de "antropologia da natureza" no prestigioso Collège de France, e eu sempre me perguntei como os seus colegas das ciências naturais conseguem ensinar os seus próprios cursos ao lado daquilo que para eles deve parecer uma fonte de material radioativo.

A preocupação de Viveiros de Castro de sua bomba ter sido desativada talvez esteja equivocada: um novo período de florescimento é aberto para a antropologia (ex-física e ex-cultural) agora que a natureza deixou de ser um recurso para se tornar um assunto altamente contestado, no momento mesmo, por acaso, em que a crise ecológica - um assunto de grande preocupação política para Viveiros de Castro no Brasil - reabriu o debate que o "naturalismo" tentara prematuramente encerrar.

Mas o que é ainda mais gratificante de ver numa disputatio como esta é o quanto nós nos distanciamos da categoria moderna e, depois, pós-moderna. Certamente, a busca por um mundo familiar é infinitamente mais complexa agora que tantos modos diferentes de habitar a terra ficaram livres para se deslocar. Mas, por sua vez, a tarefa de compor um mundo que ainda não é familiar está claramente colocada para os antropólogos, uma tarefa que é tão grande, tão séria e tão recompensadora quanto qualquer coisa com a qual eles tiveram que lidar no passado. Viveiros de Castro apontou para isso em sua resposta a uma questão vinda da plateia, usando uma espécie de aforismo trotskista: "Antropologia é a teoria e prática de permanente descolonização". Quando ele acrescentou que "a 
antropologia hoje está largamente descolonizada, mas a sua teoria ainda não é descolonizadora o suficiente", alguns de nós na sala tivemos o sentimento de que, se este debate for indicativo de algo, nós podemos finalmente estar chegando lá.

\section{Referências}

Viveiros de CASTRO, E. (1992). From the enemy's point of view: Humanity and Divinity in an Amazonian society. Chicago, University of Chicago Press.

Descola, P. (2005). Par delà nature et culture. Paris, Gallimard.

Recebido em março/2011

Aprovado em junho/2011 